\title{
Discourse Particles in Malaysian English
}

\section{What Do They Mean?}

\author{
Li Chia Tay \\ Universiti Putra Malaysia \\ lichiatay@gmail.com \\ Mei Yuit Chan \\ Universiti Putra Malaysia \\ cmy@upm.edu.my \\ Ngee Thai Yap \\ Universiti Putra Malaysia \\ ntyap@upm.edu.my \\ Bee Eng Wong \\ Universiti Putra Malaysia \\ bee@upm.edu.my
}

\begin{abstract}
Regional varieties of language, often a result of language contact, possess various characteristics, such as borrowed words, and often structures, sounds, and meanings transferred from one or more languages. The variety of English used in informal contexts in Malaysia known as Malaysian English contains localized features resulting from contact with languages spoken by the local indigenous populations as well as the Chinese and Indian diaspora in this Southeast Asian nation. A prominent feature of Malaysian English is the presence of discourse particles (such as lah, meh, and lor) that are not found in the standardized form of English and that are often unintelligible to people unfamiliar with them. Using communication on Facebook by Chinese Malaysian young adults as data representing real-life, informal talk in a computer-mediated environment, this article examines the multiple functions of Malaysian English discourse particles and proposes a framework for interpreting their meanings when used in communication.
\end{abstract}




\section{Keywords}

discourse particles - Malaysian English - regional variety of language - pragmatic functions - computer-mediated communication - Chinese-Malaysian young adults

\section{Introduction}

Ok lah ... forgive you lah! An utterance such as this may sound strange to people who are not familiar with the English spoken in Malaysia and its neighbour Singapore, but this is an example of the type of English commonly encountered in informal social interactions among Malaysians. Malaysian English, a variety of English spoken by Malaysians, contains localized features that differ from the standardized form of English and, therefore, is largely unintelligible to people who are not from this geographic region. Developed as a result of language contact with the local languages spoken by its multi-lingual and multi-ethnic society, consisting of the various indigenous populations and the Chinese and Indian diaspora in the country, ${ }^{1}$ Malaysian English has its own localized vocabulary, distinct phonological features, intonation patterns, syntactic structures, and pragmatic features (Baskaran 2008a and b; Pillai and Kamaruddin 2006). With the exception of interactions in highly formal contexts, Malaysian English, with its set of unique discourse particles such as lah, meh, lor, hor, wei, and leh, is used pervasively in oral conversations at almost all levels of society. ${ }^{2}$ While in the past and to some extent the present, too, Malaysian English has been 'vilified' by many educationalists as a 'non-ideal' form of English attributed to a poor command of the language (see, for instance, Muniandy et al. 2010), sociolinguists, on the other hand, have held that regional varieties of language evolve to fulfil purposes of communication that are meaningful to people experiencing interaction between languages in the local environment.

Many Malaysians, especially those residing in the urban areas, speak the standardized form of English; however, this does not preclude them from using Malaysian English when interacting informally with friends and colleagues,

1 Malaysia consists of Peninsular Malaysia and Sabah and Sarawak. It comprises approximately 28.3 million people with three major ethnic groups: Malay (67.4\%), Chinese $(24.6 \%)$, and $\operatorname{Indian}(7.3 \%)$; other groups are for instance Iban and Dusun (0.7\%) (Department of Statistics Malaysia 2010).

2 See, for instance, Hassan and Hashim 2009; Muniandy et al. 2010; Shamsudin 2006; Kuang 2002; Dumanig and David 2011. 
mainly for the purpose of conveying attitudes and stances related to identity and interpersonal relations the 'local' way.

Because of Malaysia's and Singapore's geographic proximity and shared historical background, ${ }^{3}$ the informal variety of English spoken in these two countries shares a number of similar features, ${ }^{4}$ and to most observers Malaysians and Singaporeans appear to use the same colloquial code without any problems with understanding each other. In describing Singaporean English as a close relation to Malaysian English, Leimgruber (2013:120-1) posits that due to the shared history pertaining to the birth of Malaysia and Singapore, the ethnic composition of Singapore and, hence, the core linguistic knowledge of its people is similar to that of Peninsular Malaysia, its closest neighbour, albeit in different proportions. The most common languages spoken at home by resident Singaporeans, based on data published from 1980 to 2011 (see Leimgruber 2013:120), are English, the southern Chinese languages, Malay, and Tamillanguages which are commonly spoken in Malaysia as well. This similarity has allowed for research in both Malaysian and Singaporean English to complement one another as well as foster a rich environment for discussion on the two forms of English, as the debate on whether these two languages are regarded as distinct varieties or 'part of a dialect continuum' (Leimgruber 2013:121) is still ongoing.

This article focuses on one of the more prominent aspects of Malaysian English, that is, the use of discourse particles adopted from local languages and incorporated into informal conversations in English. While there appear to have been disagreements among scholars about whether these discourse particles have 'meanings' or 'functions' (see Wong 2004), entering into the theoretical debate on the nature of meaning is not within the scope of this article. We adopt the view that discourse particles perform pragmatic functions to convey pragmatic meanings, particularly attitudinal meanings brought about by their use in communication.

Data for the study were obtained from conversations between Chinese Malaysian young adults on Facebook, as the type of communication among friends and family on this platform is mostly conducted in an informal style. Our research questions include: What Malaysian English discourse particles are used, and how are they used, in a computer-mediated environment by this group of Malaysians? Particularly, we are interested in examining the functions

3 Singapore, together with Sabah and Sarawak on the island of Borneo, merged with the then Federation of Malaya to form Malaysia in 1963. However, in 1965 Singapore separated from Malaysia and became a sovereign nation.

4 Leimgruber 2013; Ooi 2001; Goh 2003; Platt and Weber 1980; Platt, Weber and Lick 1983. 
of the particles used in communicating attitudinal meanings via a channel of communication that has inherent restrictions on the use of non-verbal cues to express such meanings.

\section{Discourse Particles}

A discourse particle is defined as a linguistic unit that conveys more than what is said in an actual utterance (Platt 1987), in such a way as to convey a speaker's attitude or stance, and to guide the hearer towards the speaker's intended meaning (Aijmer and Simon-Vandenbergen 2003). Ostman (1982:152) posits that discourse particles, which are included in the class of expressions referred to as pragmatic particles, as with other elements of language such as prosody, gestures, and certain grammatical devices, function to 'implicitly anchor the act of communication to the speaker's attitudes towards aspects of the on-going interaction'. With reference to Malaysian English discourse particles, Hassan and Hashim (2009:43-4) assert that the particles function to convey emotions and attitudes, such as 'to soften a directive, place emphasis on a statement or word, and affirm a statement or turn a statement into a question'.

Discourse particles are optional items because their inclusion or omission does not affect the grammatical 'correctness' (Ler 2006) or the propositional content of an utterance. For example, the common discourse particle $l a h$, when used in the utterance I'll be there lah, merely brings an added dimension of interpersonal meaning to the utterance, without causing significant changes in the propositional meaning of the host sentence I'll be there. Discourse particles, therefore, are useful as linguistic devices that guide speakers and hearers to particular and relevant interpretations of interpersonal meaning in utterances and to manage interactions. Further, while they may mark semantic relations between segments, they carry little or no semantic meaning themselves (Lee 1998), and hence, do not contribute to the truth conditions of an utterance (Ler 2006). Finally, they are multifunctional as they have different uses and meanings in different contexts. ${ }^{5}$

5 Lam 2008; Platt and Ho 1989; Schiffrin 1987; Loke and Low 1988. 


\section{Tone and Meaning of Discourse Particles}

Based on observations of the existence of similar particles found in the local languages in Malaysia, many Malaysian English discourse particles can be traced to their possible sources, which are mainly the Malay language and Chinese languages such as Mandarin, Hokkien, Teochew, and Cantonese. ${ }^{6}$ The particle $k e / k a h$ is said to have originated from Malay, $o$ from Mandarin, leh from Hokkien and Teochew, and geh from Cantonese (Lim 2007b). Particles that originate from the Chinese languages can be easily distinguished as they are spoken in distinctive tones, a characteristic of Chinese languages. Lee (2007) observes that particles carry tones much the same way as Chinese words. As noted by Kwan-Terry (1992), Loke and Low (1988), and Wong (2004), particles uttered in different tones serve different functions, and it is commonly observed that the particles are pronounced in particular tones in a regular manner to convey particular meanings. Other researchers, for example Gupta (1992, 2006a) and Goh $(2000,2003)$ prefer to describe the variation in the pronunciation of the particles as a feature of the intonation contour of the utterance.

While it is conceded that tonal and prosodic features do provide important clues to a hearer's interpretation of the meanings carried by the particles, they are nevertheless not entirely essential in written communication. In the written mode of communication, these particles are used without any indication of tone, and yet are perfectly intelligible to the interlocutors. The intended meanings of speakers are decoded by hearers based entirely on their shared understanding of the use oflanguage in context, without the benefit of tone. However, as in all human interactions characterized by the use of implicature and inference, meanings perceived by a hearer can only be an approximation of what is intended by the speaker, with the hearer collating and processing information deemed relevant in the communication situation (Sperber and Wilson 1995). When the tone of the discourse particle is absent from the communication, as is the case in computer-mediated communication, the interlocutors depend on other clues in the pragmatic context to derive at the meanings intended. The tone of the particle is inferred by the hearer based on the relevance of context.

6 The identification of the source language of a particle is based on a combination of observation and subjective judgement. Most researchers concede that the source of certain particles may not be easily distinguished, but may be more confident in positing the roots of certain other particles. For example, Lim (2007a) suggests that the source languages for the particle lah could be Malay, Hokkien, or Cantonese, while Kwan-Terry (1991) argues that hor is very likely an element transferred from Cantonese. 
Interlocutors using discourse particles share a common understanding of the pragmatic role played by each of the particles, and use this understanding to search for meanings in utterances that fit their expectations of what is relevant in the communication. In the current study, which sought to describe Chinese Malaysian youth's use of Malaysian English discourse particles in computermediated communication, the meanings conveyed through the use of the particles are identified from the contexts of the conversations between interlocutors, conceding, however, that interpretation would have been much easier and more accurate if the tone of the particles and intonation of the utterances had been available. As particles are clues to interpersonal meanings that are tacitly conveyed in interactions, a fair amount of inference is required to understand and make explicit these meanings. It is not possible, for example, to obtain an objective explanation on the function of a discourse particle from someone by asking him or her about this in an interview-for the use of particles in communication, as is the case with most language use in interaction, is carried out rather unconsciously.

\section{Malaysian and Singaporean English Discourse Particles: Some Empirical Studies}

Studies on Malaysian English discourse particles ${ }^{7}$ are few compared to those conducted on Singaporean English. ${ }^{8}$ As Singaporean English has many similarities with Malaysian English, and due to the sparse research on Malaysian English discourse particles, research conducted specifically on the discourse particles of these two related varieties of English is discussed to provide a brief background of work previously done. Most of the work done on Malaysian English particles has focused on particles attributed to influence from the Chinese languages. Exceptions are the particle lah, whose origin is uncertain; kan, which is derived from Malay; and bah, which has been postulated to have originated from Mandarin or the Borneo languages (see Hassan et al. 2012; Leimgruber 2016). Further, as most of Singapore's population is ethnic Chinese, the particles in Singaporean English are predominantly those originating from the Chinese languages. The influence of non-Chinese languages such as Malay and Tamil on the lexicon, phonology, and grammar of Malaysian English is

7 For instance, Hassan and Hashim 2009; Kuang 2002; Muniandy et al. 2010; Shamsudin 2006.

8 For instance, Gupta 1992; Kwan-Terry 1978; Lam 2008; Ler 2006; Lim 2007a; Low and Brown 2005; Low and Deterding 2003; Wong 2004. 


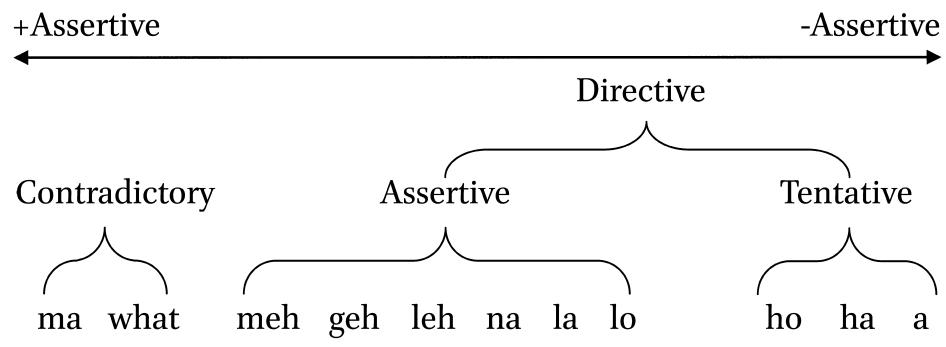

FIGURE 1 Scale of assertiveness of pragmatic particles GUPTA 1992:37

well-documented and has been extensively described; however, their influence on the specific word class identified as the discourse particle is still relatively unknown.

Hassan and Hashim's (2009) extensive work on Malaysian English, based on a corpus of two million words derived from blogs, chats and instant messages, e-mails, and text messages, highlights the use of four particles: bah, meh, ler, and $l a$. These particles are said to have originated from Malay, Chinese, and the local Sabahan languages, and they carry out specific functions to convey emotive attitudes. Kuang (2002) — with her description of the functions of the three particles lah, ah, and hah, based on observed informal conversations in different settings - further adds to existing knowledge about how Malaysians use the particles. She concludes that discourse particles play an important role as useful resources that enable speakers to convey their intentions in different ways, such as to get their messages across without appearing too direct, intimidating, or aggressive.

In her research on Singaporean English, Gupta (1992) identifies eleven particles - ma, what, meh, geh, leh, na, la, lo, ho, ha, and $a$-from an analysis of data comprising 18 hours of recorded casual conversations of two Singapore Chinese families. The children in these families speak Singaporean English as their first language, but have been exposed to Hokkien, Teochew, Mandarin, and Cantonese as well. Based on her research, Gupta concludes that particles can be placed on an assertiveness scale ranging from contradictory and assertive, to tentative, which indicates their broad functions (see Figure 1). Ma and what are said to convey contradiction; $m e h$, geh, leh, $n a$, la, and lo express assertiveness, whereas $h o, h a$, and $a$ convey tentativeness. When used in directives, for example, particles in the 'assertive' group indicate commands, whereas those in the 'tentative' group indicate 'softer' requests.

In a later work, Gupta (2006b) expands on her analysis by proposing that the discourse particles can in fact be viewed as devices that signal epistemic 
modality. They serve to index the speaker's degree of confidence or commitment towards the proposition in an utterance, a function which is in line with the notion of the degree of assertiveness. Other notable Singaporean English researchers who have studied the discourse particle are Low and Brown (2005), whose description of the functions of the eight most common particles they have identified in Singaporean English ( $a$ h, eh, hor, lah, lor, ma, meh, and what) has been insightful. In addition, Ler (2005) argues that each particle may be assigned a core meaning, although it may project several different but related meanings when used in different contexts. Ler's stance reflects that of Wong (2004), who argues for a unique semantic definition of each particle (or each variant form of a particle), which he asserts ought to be stable across contexts. In proposing the Wierzbickan approach (known as the NSM approach) to the study of meaning (see Besemeres and Wierzbicka (2003) and Wong (2004) for its application in the analysis of Singaporean English discourse particles), he claims that the problem of particles appearing to have overlapping functions when analysed from a functionalist perspective would be resolved if the inherent meaning of the particles were to be explicated first.

Attempts to define the functions of discourse particles have generally advanced in two ways. The first, and the more widely attempted, was to try to provide as narrowly as possible, highly differentiated descriptions for individual particles. An example of this would be a formulation such as 'to draw the addressee's attention to the speaker's mood or attitude, and [appeal] to the addressee to act in such a way that will accommodate this mood or attitude' (Wee 2010:1). Some other descriptions are more general, such as 'to emphasize a topic' (Lee 2007:13), perhaps as a result of attempts to cover as many contextual situations as might be encountered when using a particular particle. The second, and less frequently attempted way to define particles, would be to categorize specific particles into types, based on broad categories of functions. This is exemplified by Gupta's (1992) assertiveness scale, which places particles into a kind of system that indexes their properties as relative to each other along a continuum. Ler's (2005) and Wong's (2004) work, on the other hand, although different in their individual approaches, shares the general assumption that there is an identifiable core, or unified meaning, that can be attributed to each particle. These two approaches to analysing discourse particles, however, are by no means mutually exclusive. It is common for researchers to deal with the specific meanings of particles in various contexts before arriving at an attempt to provide an overview or abstraction of meanings attributed to the particles.

As this study sets out to describe attitudinal meanings that speakers convey when using particles in communicative acts, a functional orientation to the 
analysis is adopted. It is pointed out that identifying and labelling functions or pragmatic meanings is not a straightforward project. The same particles used in similar contexts may have their functions labelled differently by different researchers. This is not inconceivable, as the understanding of pragmatic meanings is determined by one's interpretation of the contextual variables connected with each unique interaction.

\section{Method}

The data for analysis are comprised of a total of 200 Facebook conversations involving 499 unique interlocutors (unique screen identities). The conversations were searched and collected from the wall post archives of 20 Chinese Malaysian Facebook users' profiles over a two-week period, beginning with the most recent entries. The interlocutors in the conversations consisted of the profile owners and their commenters. The profile owners were selected via the first author's Facebook account. The 20 subjects selected live in urban and suburban localities, are computer literate, and speak English fluently. Selection of the conversations was purposive, guided by these criteria:

(1) The 20 Facebook users, who were friends of the first author, were Chinese Malaysian young adults between 20 and 30 years of age. Their Facebook profiles were checked to ensure they were in 'active' status during the period of data collection. Permission was obtained from these 20 people to access their archived conversations for this research. They were assured that all names in the conversations would be anonymized. All 20 participants gave their consent.

(2) Chinese Malaysian status of commenters: Most of the commenters in the conversations were not known to the authors. The profile pages of the commenters were checked to determine their background based on their names, photographs, and their descriptions of themselves. Only information placed in the public domain by the commenters was accessed. While it is conceded that individuals do use fake online identities, such practice is less common in Facebook accounts that are set up for keeping in touch with friends and family, characterized by strict privacy settings. The particles in the utterances of commenters who fulfilled the criterion of Chinese Malaysian young adults were included in the analysis.

(3) Ten conversations from each of the selected Facebook users' profile pages were collected. Conversations were selected if they were in English, consisted of at least six turns, and contained at least two Malaysian English 
discourse particles. This was to ensure that there would be sufficient particles sampled, and a rich enough context available to the analyst to determine the functions of the particles used.

Past descriptions of the functions of discourse particles in the Malaysian and Singaporean contexts were used as a guide to inform data analysis, but not as a fixed template into which the data were made to fit. Analysis of the data was primarily inductive, and allowed for comparison between earlier and later formulations and ongoing fine-tuning of interpretations as the analysis progressed.

\section{Principles that Guide the Analysis of Discourse Particles}

For any analysis of language and discourse, it is advantageous for the analyst to understand the language that is being analysed. Being a member of the speech community facilitates analysis, as the analyst would be able to discern the nuances in the meanings of language where non-members might not. Attempting to describe functions of discourse particles which are essentially non-lexical words that derive their meanings from their host utterance and pragmatic context is a slippery task, as such meanings often operate at the subconscious level and require a deliberate effort to uncover. All four authors of this article are members of the speech community of Malaysian English speakers and are therefore familiar with the use of Malaysian English discourse particles. Even when using previously available descriptions of discourse particle functions as a guide, the authors have had to rely to a large extent on their intuition as speakers of the language to interpret the pragmatic context and derive the functions arising from the data. However, there are several principles that the authors formulated along the way and found helpful for analysis. The analysis of the data for the study depended to a large extent on inductive examination guided by these principles.

\section{Omission Rules}

First, particles that do not carry attitudinal meaning in the utterance/sentence, but merely serve a syntactic or grammatical function, are omitted. For example, the particle mah could be used both as an attitude marker as well as a syntactic marker. In the utterance You like laksa mah? 'Do you like laksa?,' 9 the function

9 Laksa is a popular local dish consisting of rice noodles and spicy, fish-based soup. 
of the particle is purely syntactic, that is, it is used as a question marker. When the word mah is removed, the sentence becomes a statement: You like laksa. As mah is believed to be derived from Mandarin, Chinese speakers sometimes use it to construct questions in the same way as it is used in Mandarin. However, if the utterance is presented as a statement, that is, a comment rather than a question, then You like laksa mah would probably mean 'Well, I know you like laksa - that's why I bought you laksa instead of tom yam, so don't complain.' The attitude of the speaker, which can be described as 'adopting a defensive stance', is projected by the particle. The particle allows the speaker to justify their earlier action by pointing out a previously shared assumption, that is, both the speaker and the hearer agree that the hearer likes laksa. To our knowledge, the particle mah is the only particle that could be used as a neutral question marker in Malaysian English. By comparison, the particle ah is attached to questions such as You like laksa ah?, but the particle ah differs from mah in the question You like laksa mah? in that the former encodes attitudinal meaning whereas the latter does not.

While still discussing grammatical functions, elements whose sole function in an utterance is to indicate possession, are also omitted-for example, de, one, and geh. An example would be This pen is Vera de 'This is Vera's pen', where the elements $d e$, one, and $g e h$ are interchangeable in the utterance. Hence, $d e$, one, and geh are omitted from the analysis when they function as possessive markers.

Second, certain particles are used in direct translations of a language and do not imbue the utterance with additional attitudinal meanings. For example, the particle $l e h$, which is believed to be derived from Hokkien and Teochew, can be translated as 'what about' in certain instances, for example in the utterance stretch I prefer to meet on the third day. You leh? This is understood as 'I prefer to meet on the third day. What about you?' Such cases are also excluded.

Third, only the particles that occupy the utterance-final slot are included in the analysis. This is because linguists have expressed doubts about whether utterance-initial particles play similar roles to utterance-final ones, as they occupy different grammatical slots. The particle found in the utterance-initial position in the data, namely eh (for instance, eh I thought Sim is going with us), has been excluded.

\section{The Contribution of Meaning from the Discourse Particle and Its Host Utterance}

Another difficulty encountered in describing the meanings of discourse particles is the conflation of meanings from both the host utterance and the particle itself. Meanings are contributed both by the discourse particle as well as the 
utterance to which it is attached. For example, in the utterance Buy this lah, the meanings of the utterance with and without the particle are different. Without the particle, the host utterance Buy this may be interpreted as a directive, a speech act that reflects a highly assertive tone. With the addition of the particle lah, the utterance is modified into a polite request or a friendly encouragement to someone to buy a certain object. However, in an utterance where the meaning of the host sentence is close or similar to that attributed to the particle, such as I understand how you feel lo, where both the host sentence/utterance and the particle appear to converge towards the meaning of 'expressing sympathy', one tends to conflate the meaning contributed by the particle with that of the host utterance, and assign the function 'to express sympathy' to the particle. But to speakers of Malaysian English, the utterance expressing sympathy clearly differs depending on whether it is spoken with or without the particle lo. By checking the difference in meaning expressed if the particle were to be omitted, the function of the particle can be analysed as 'to indicate sincerity in an expression of sympathy', where the attitude of being sincere is highlighted. Using this heuristic, the meaning contributed by the particle would be the attitudinal difference between the resulting meanings of the utterance with and without the particle. Accordingly, labels such as 'to disagree', for example, that appear only to describe the meaning expressed by the preceding or host utterances, would be deemed inadequate for our purposes:

A: Oh that's Cheryl.

B: No that's not Cheryl, that's Rachel $a$. (function of $a$ given as 'to disagree') GUPTA 1992:49

\section{Malaysian English Discourse Particles and Their Frequencies}

Twenty discourse particles were found in the data, appearing in total 1,049 times (Appendix, see Table 1) in the 200 conversations with 499 interlocutors. In comparison, Ler (2005:36) found only ten particles in the Singaporean data, which is the spoken part of the ICE-SIN corpus comprising 60o,0oo words, while Gupta (1992) found eleven particles. If these ten or eleven particles were to be accepted as the full set of particles in Singaporean English, this would mean that the sociolinguistic environments of Malaysia and Singapore differ significantly, as clearly various other particles from the local linguistic stock have found their way into Malaysian English.

The most frequently used particles found in the data are lah/la (35.4\%), followed by lor/lo (17.8\%), and leh (12.6\%). With published work by Muniandy 
et al. (2010) and Low and Deterding (2003) showing lah as the most frequently used particle in both Malaysian and Singaporean English, and Besemeres and Wierzbicka (2003) positing that lah is the most salient of the particles used by Singaporeans, the iconic status of lah in representing Malaysian and Singaporean English is almost assured. $.^{10},{ }^{11}$ On the other hand, the least frequently used particles are kan and nah ( $0.1 \%$ for both particles). This is probably because kan is derived from the Malay language and therefore its influence on Chinese Malaysian speakers is less apparent. While Ler (2005:36) found nah to be more frequent than leh, mah, and meh, it is quite clear the particle nah is not a favourite among the Malaysian speakers in the study.

Out of the 20 particles found in the data, ten (lah, lor, leh, ma, ah, meh, what, hor, $y a$ and $n a h$ ) have been described extensively in previous studies. The remaining ten particles (wor, de, one, o, wei, ke/kah, bah, gua, geh, and kan $)^{12}$ have not been given much attention previously and so are relatively unknown. Although several of these particles—wei (Shamsudin 2006), one (Muniandy et al. 2010) and geh (Gupta 1992) — have been mentioned by past researchers, their functions have yet to be explicated. The appearance of these under-researched particles in the Malaysian data shows that Malaysian English has decidedly more varied particles than is evidenced by the body of previous work on the subject.

\section{Pragmatic Functions}

Comparing functions across and within particles, we found that formulating 'core meanings' (Wong 2004; Ler 2005) or the central overarching functions of particles was problematic, as their functions were many and varied, and context-specific. So, too, would be attempting to put individual particles into categories or on a scale (see, for instance, Gupta 1992, 2006b), as to do this would mean presupposing that a particle has a composite function, and that

10 There have been different findings regarding the most salient particles in Singaporean English. For example, Gupta $(1992,2006 \mathrm{~b})$ found the particle $a h$ to be the most frequently used in spoken Singaporean English.

11 This is not to deny the salience of the less frequently used particles, as the existence of the whole set of particles forms the unique characteristics of what is known as Malaysian English.

12 At the time of the writing of this article, the particle $b a h$ has been found as a particle in Singaporean English and a comprehensive discussion of its functions in Singaporean English was published by Leimgruber 2016. 
this composite function could only be described relative to that of another particle on some common inherent quality.

An observation was made during the analysis with regard to the labelling of functions. It became clear that the function 'to establish rapport' or 'to show intimacy' as used in past studies (for instance, Low and Brown 2005:177) overlaps with most other functions that convey positive affect, such as 'to convey friendliness' or 'to express sympathy'. Also, in cases where the potential for conflict is mitigated by the particle, such as in an attempt to minimize interpersonal costs while expressing disagreement, there is, too, the implicit notion of 'keeping the rapport from being diminished'. Hence, 'establishing rapport or intimacy' was found to be an unsuitable description of a specific function, but appears to be a function operating at a higher conceptual level. On the other hand, there were also functions found that were the opposite of rapportbuilding or rapport-maintaining, such as 'to express irritation' (Gupta 1992:43) or 'to show disapproval and indicate displeasure' (Kuang 2002:8), which essentially work to distance one interlocutor from another. Following these observations, we concluded that discourse particle functions can be more clearly understood when viewed through the frame of two mutually exclusive categories of socio-pragmatic functions, which are 'to increase social distance' and 'to reduce social distance' (see Tables 2 and 3 in the Appendix). It became necessary to analyse the functions of individual particles separately, as a single particle may have functions that act in opposite directions. For example, one of the functions of lah, which is 'to soften an order or advice', reduces social distance, while another of its functions, 'to show disapproval, contradiction or disagreement in a harsh manner', has the opposite effect on social relationships.

\section{Discourse Particles in Context: Reducing and Increasing Social Distance}

The job of discourse particles in Malaysian English appears to be to maintain social relationships in oral communication, or, in the context of this study, social-media communication. The function of reducing social distance would include situations where an interlocutor expresses politeness and tentativeness in making requests, shows affiliation or willingness to affiliate, and so forth. In situations where conflict is inevitable or anticipated, an appropriate and timely particle can also be used to diffuse tension and deflect a potential confrontation. This would include providing justification or rationalizing one's behaviour or assumptions, aligning oneself with others, reducing status or 
power differences, or seeking affirmation. Hence, one may make an utterance that could seem rude or insensitive, and try to mitigate the potential damage with a particle, for example, You eat a lot hor.

Most of the discourse particles in the data were used for the purpose of reducing social distance. However, particles were also used to increase social distance, which is essentially to emphasize differences instead of align with one's interlocutor. It may range from the act of expressing irritation to that of rebuking someone for making a presumptuous remark. While speakers may make an assertion in a manner that appears sufficiently polite, they may add a particle to the utterance that will not so subtly betray their indignation towards the interlocutor, for example, in the utterance I have completed it lah! 'I have completed the work-don't annoy me with your nagging'. A particle that is well known for being used to rebuke nosy parkers is meh. Famously combined with the single word 'cannot', it forms the iconic expression cannot meh (or beh sai meh in Hokkien), which conveys the rebuttal 'You got a problem with that? Mind your own business' to unwelcome comments. The communication situation illustrated below is by far the most hostile that could be found in the data:

Interlocutor A: $\quad$ crazy $a r==$

Interlocutor B: cannot meh?!

Interlocutor A: Din say can't (I didn't say you can't)

Interlocutor B: then?

Interlocutor B's hostile challenge to A (cannot meh?!) is clearly understood by A, resulting in his apologetic retraction of his initial intrusive comment to $\mathrm{B}$. в is still dissatisfied with this retraction and presses on with another hostile challenge (then?), which requires A to further explain himself.

Tables 2 and 3 (see Appendix) list the particles and their functions, with examples extracted from the data. For a more detailed explanation of the functions, three particles are selected here for illustration purposes. They are lah, lor, and leh, which are the three most frequently used particles. Out of the three particles, lah and leh can be used to perform both the functions of reducing as well as increasing social distance.

\section{The Particle Lah}

One of the pragmatic functions of lah (sometimes spelt $l a$ ) that acts to reduce social distance is to soften an order or advice. For example, in the utterance You see doctor lah (refer to Conversation 1), lah serves to soften an advice so that it does not sound too imposing and abrupt. In Conversation 1, interlocutor B is 
gently advising his friend $\mathrm{A}$, who is complaining about not feeling well, to see a doctor about his ailment. If the particle lah were to be omitted, the utterance would seem more like a directive, an act that would be rather inappropriate when one is trying to express concern for a friend.

Conversation 1:

Interlocutor B: ewww! It didn't taste dubious? What about prawn mee then? hehe.

You ok now?

Interlocutor A: no lar not from the crab.. already feeling sick in the morning.. prawn mee, dare not eat after that, it reminds me of puke! haha.. still feel shitty but ok lar..

Interlocutor B: You see doctor lah

On the other hand, another function of $l a h$, which can be placed in the category of increasing social distance, is showing exasperation with someone in a harsh manner. The use of lah to express exasperation and unhappiness at being rejected is illustrated in Conversation 2, which starts with an interlocutor A (male) extending an invitation to his friend в (female) to meet up: tot can ask you out tim de 'I thought of asking you out' (refer to Conversation 2 below).

Conversation 2:

Interlocutor A: no la ... tot can ask u out tim de ... mana tau sudah balik pula today i $3.30 \mathrm{pm}$ baru balik ...

Interlocutor B: Oo..next time oso can ... not tired ar ... y u are working de?? Interlocutor A: next time next time ... dunno how many next time liao la ... tired la ... today's work long story lo ... wait you "next time" come first then i tell u la ...

Feeling embarrassed, possibly at the invitation which might cause a loss of face as it is issued in public (and perhaps, too, because she doesn't have any interest in the person inviting her), interlocutor B skilfully declines the offer by taking a rain check (Oo.. next time oso can) and tries to mitigate her rejection by showing some concern for B (not tired ar ...). This angers the inviter, who then scolds the invitee by lashing out with the utterance Next time next time ... dunno how many next time liao la ... 'Next time next time! How many times have you given me that?' From this, it becomes apparent that his overtures to the female 
interlocutor have been rejected many times before. The particle lah expresses his extreme unhappiness at being rejected yet again. This unhappiness is confirmed by his use of double quotation marks enclosing the phrase next time (wait you "next time" come first then i tell u la ...) as a sign of sarcasm towards the girl's insincere promise to meet up with him.

\section{The Particle Lor}

The particle lor or lo in the data is used only for reducing social distance. One of its functions is to indicate sincerity in an expression of sympathy. We mention the utterance I understand how you feel lo by way of illustration (see Conversation 3). In this conversation, the interlocutor a complains that her salary is too low, and her workload too heavy. Her friend в expresses sympathy by using $l o$ in her reply. The effect of using $l o$, to a speaker of Malaysian English, is an increased emphasis on the feeling of sincerity and 'togetherness', as in 'I am with you in this', raising the degree of sympathy expressed a notch or two higher than if the particle were not used.

\section{Conversation 3:}

Interlocutor A: work like cheap [omitted].. shit!!!

Interlocutor B: wah, never see u so angry before. Relax.

Interlocutor A: really out of control. really fed up.

Interlocutor B: I understand how you feel lo

Besides that, lor is also used to soften an advice, so that it does not sound too imposing or abrupt. In one of the conversations, the interlocutor A calls her brother pui kia 'fat boy' (see Conversation 4). Her mother, who is also a party in the conversation, advises her daughter not to call her brother 'fat boy', as it would make him angry: don't call your gorgor 'elder brother' pui kia 'fat boy', angrylo.

\section{Conversation 4:}

Interlocutor A: eyelid twitching all night. Is it a sign of bad luck? :s

Interlocutor B: don think 2 much ... mayb wanna kena lottery d, haha

Interlocuter C: u not enuff sleep lar

Interlocutor A: pui kia, u're d one who think too much. Lol haa impossible. i sleep almost more than $8 \mathrm{hrs}$ everyday so should be $\mathrm{d}$ other way around. lol

Interlocutor D: u dont called yr gor gor pui kia, angry lo 
The particle lor here is used to soften what appears to be an admonishment given in the form of an advice. From an understanding mother, this is a strategy to avoid publicly embarrassing her daughter (face-saving strategy), as the conversation could be viewed by many of her daughter's Facebook friends.

\section{The Particle Leh}

The particle leh in conversations 5 and 6 was used for both reducing and increasing social distance. One of the functions of leh in reducing social distance is to express politeness when performing acts that could potentially damage a relationship, such as to contradict or disagree. To illustrate: the interlocutor A excitedly asks his friend to click on the YouTube link that he has posted (see Conversation 5). However, his friend B, who is at work at the office at the time, replies he cannot watch the video as there is CCTV (closed circuit surveillance camera) at his office: I cannot watch now leh. Got ccTV in office here.

\section{Conversation 5 :}

Interlocutor A: cant get enough of this..

Waiting for the End (Official HD) www.youtube.com

Interlocutor B: when is the next $\mathrm{K}$ session..hehehe

Interlocutor A: you got watch the link I post? faster watch

Interlocutor B: I cannot watch now leh. Got CCTV in office here.

To minimize the hurt feelings that may arise from not taking up his friend's well-meaning suggestion, the particle leh is used when rejecting the suggestion to watch the video. Although one may argue that providing a reason or explanation (that is, Got ccTV in office here) when rejecting a suggestion is in itself a face-saving strategy in social conversations, the use of leh in this context serves to further increase the level of politeness. This politeness is achieved by de-emphasizing the speaker's contradiction of his friend's assumption that he should be free to do his friend's bidding at that very moment.

Apart from reducing social distance, leh can also be used to contradict someone in a harsh manner, which falls under the category of increasing social distance between interlocutors. For example, I don't know where is he leh! (see Conversation 6).

Conversation 6:

Interlocutor $\mathrm{A}: \mathrm{HH}, \mathrm{NW}$ still in $\mathrm{KL}$ ?

Interlocutor B: I don't know where is he leh! 
In Conversation 6, the interlocutor B is asked about her ex-boyfriend's whereabouts, because the enquirer $\mathrm{A}$ is not aware that she has broken up with her boyfriend. To show her irritation at being reminded of someone whom she would rather forget, she answers that she does not know where he is in a harsh manner, without considering that her friend may feel embarrassed for asking the question. In fact, the intention of this rebuke is likely to warn the questioner to keep her distance where the sensitive topic about her ex-boyfriend is concerned. Without the addition of leh, her indignation or anger would not have been reflected in the utterance.

\section{Conclusion}

This study has shown that a large number of Malaysian English discourse particles are used by Chinese Malaysian young adults when communicating in English on Facebook to express a variety of attitudinal meanings. The particles work as linguistic devices for speakers to convey attitudinal meanings such as affect and stance, and for hearers to be guided to particular and relevant interpretations of the speaker's attitude. Above all, the particles are pragmatic devices that speakers exploit to manage social relationships in interactions.

An important point on which this study departs from previous research is the proposed categorization of the functions of the discourse particles, as opposed to the categorization of the particles themselves, into two superordinate functions, which are to reduce and to increase social distance. The implication following this framing of functions is the departure from the implicit assumption that the cognate functions of an individual particle must be somewhat related or similar in some ways. The findings of this study do not support this assumption.

In the game of managing social relationships, speakers expertly use particles in their utterances to index their attitude towards both the proposition and the hearers. By attaching these utterance-final particles, a speaker may mitigate a potentially damaging utterance on the one hand, or highlight their negative evaluation of the hearer even when no negative words are uttered on the other hand. The ways in which particles serve interlocutors' interactional goals in increasing and decreasing social distance are questions that researchers of Malaysian English may wish to further explore.

An interesting observation from the study is that the instances in which the particles are used for reducing social distance appear to be more common compared to those for increasing social distance. This might be explained by the medium and the platform on which the communication is taking place. 
Facebook, being a public space for the congregation of friends and family, necessitates that face-saving and relationship-building discourses rule over confrontational ones. In more hostile discourse contexts, it is expected that the particles would play a bigger role in conveying negative speaker stances.

This article does not make claims about the influence of the medium of communication on the use of discourse particles, as it is out of its purview to do so. However, it is common knowledge from the vast literature on language use on the Internet that interlocutors make up for the lack of voice cues and facial expressions in text-based conversations by using various strategies to express attitude and affect, such as the use of emoticons, capitalizations, unusual punctuation, and so forth. In the example illustrated in the previous section of this article, the speaker's ire in her utterance I don't know where is he leh! could have been expressed through capitalization, or by attaching an appropriate angry-face emoticon. Instead, the speaker used the text-based particle leh as the means for expressing her indignation. This should not be too surprising, as the discourse particle is, after all, part of the speaker's language (Malaysian English) and informal Internet communication resembles actual face-to-face talk. Furthermore, resources such as emoticons and capitalizations are more or less one dimensional in their meanings, unlike the diverse nuances of meanings that can be achieved through a discourse particle.

The Malaysian English discourse particles and their pragmatic functions described in this study are based on the conversations of Chinese Malaysian youth on Facebook, the sampling type of which is non-probability. Hence, they cannot be said to represent the entirety of particles in Malaysian English or to be representative of the group being studied. Further, the data were obtained from communication in a computer-mediated environment in the written mode, which precludes being able to analyse facial expression, tone, and intonation as clues to assist interpretation. In such a situation, it is conceived that the description of functions might not comprehensively include all the possible richness and nuances of meanings, or even alternate meanings a particle may implicate when used in an interaction. However, this limitation does not detract from the significance of the current study in examining the use of the particles in computer-mediated communication, as it is native to interactions in this type of communication that interlocutors are required to conduct their conversations in the absence of facial and vocal clues.

One question, however, arises from the findings of the study, which has to do with similar functions expressed by different discourse particles. For example, the function 'to soften an order/advice' seems to be associated with the particles $\mathrm{ma} / \mathrm{mah}$, ah, $y a$, hor, and nah. At this point it is not known why a speaker might choose to use one discourse particle over another in 
instances when they appear to perform similar functions. We might postulate that it could be something to do with the Chinese language from which the particle originates, and the language group to which the speaker belongs. For example, a particle that originates from the Hokkien language (for instance, leh) may be preferred by Hokkien speakers, and a particle that is derived from Mandarin (for instance, $o$ ) may be the particle of choice for Mandarin speakers. However, bearing in mind that many of the Chinese languages share lexicalgrammatical features (for example, wei exists in Cantonese, Hokkien, Teochew, and Mandarin), it is sometimes not possible to pinpoint the exact source of a Chinese-based particle in Malaysian English (Lim 2007b). Furthermore, we also propose that the choice of particles in cases where different particles may be used to serve the same function, might be affected by the closeness of the relationship between the interlocutors, as the level of intimacy in the relationship between speakers and their perspectives towards each other are said to influence choice of language use (Eggins 1994). An example is the particle wei, which seems to be reserved only for interactions between people deemed to be 'closer' than mere acquaintances.

Our last hypothesis, which we feel might be more promising in shedding light on the issue, is the notion of non-interchangeability between discourse particles, even when the particles appear to perform the same function. There may be particular semantic, grammatical, and pragmatic features attached to particles that have not yet been explicitly described, but that constitute the tacit knowledge of members of the speech community. There are a few possibilities based on observation. First, how a speaker constructs his or her utterance in an ongoing conversation may influence the choice of particle, or conversely, the choice of particle might determine how the utterance is to be constructed. Second, the choice of particle may be influenced by the mutual language that the interlocutors commonly use when communicating in face-to-face interactions with each other. For example, if two interlocutors' mutual language is Cantonese, they would likely opt to use the particle gua (from Cantonese) to indicate uncertainty instead of $b a h$ (from Mandarin or the Borneo languages as the case may be) when speaking in Malaysian English. Next, wei is used between interlocutors who have an existing close relationship, whereas lah can be used between people at any level of closeness and familiarity. Finally, the particle $y a$ is said to be predominantly used by younger female Singaporean speakers in English utterances, and serves to index a speaker's assumption of mutual agreement between himself or herself and the hearer (Wee 2010). However, based on informal observations, it also appears to indicate a differential power status in discourse identity between the speaker and hearer, with the speaker claiming a higher position in relation to the hearer. For example, a 
mother might tell her son Be careful, $y a$, where $y a$ indexes her claimed right to give advice. Finally, in keeping with the latest developments in the discussion on discourse particles being an open class category of words, Leimgruber's (2016) argument that the use of $b a h$ in Singaporean English does not entirely resemble the use of similar elements found in Mandarin, the Sabahan languages or Bruneian English, must stimulate further debate on the evolution of language over time. These hypotheses on the connection between the origin of a discourse particle and the language group of the speaker, the mutual common language between interlocutors, the 'closeness of relationship' principle, the 'non-interchangeability' principle, and the modification of functions of discourse particles over time are yet to be verified, but point to a direction for further research.

\section{References}

Aijmer, Karin and Anne-Marie Simon-Vandenbergen (2003). "The discourse particle 'well' and its equivalents in Swedish and Dutch', Linguistics 41-6:1123-61. http:// www.degruyter.com/view/j/ling.2003.41.issue-/ling.2003.036/ling.2003.036.xml (accessed 1 July 2012).

Baskaran, Loga (2008a). 'Malaysian English: Phonology', in: R. Mesthrie (ed.), Varieties of English Vol. 4, pp. 278-91. Berlin: Mouton de Gruyter. [Africa, South and Southeast Asia.]

Baskaran, Loga (2008b). 'Malaysian English: Morphology and syntax', in: R. Mesthrie (ed.), Varieties of English Vol. 4, pp. 610-23. Berlin: Mouton de Gruyter. [Africa, South and Southeast Asia.]

Besemeres, Mary and Anna Wierzbicka (2003). 'The meaning of the particle 'lah' in Singapore English', Pragmatics and Cognition 11-1:3-38.

Department of Statistics Malaysia (2010). General report of the population and housing census 2010. Kuala Lumpur: Department of Statistics, Malaysia.

Dumanig, Francisco and Maya Khemlani David (2011). 'Malaysian-Filipino couples and language choice: International language or heritage language?', in: Dipika Mukerjee and

Maya Khemlani David (eds), National language planning and language shifts in Malaysian minority communities: Speaking in many tongues — Language shifts in Malaysian minority communities and the effects of national language planning, pp. 71-86. Amsterdam: Amsterdam University Press.

Eggins, Suzanne (1994). An introduction to systemic functional linguistics. London: Pinter.

Goh, Chuen Meng Christine (2000). 'A discourse approach to the description of intona- 
tion in Singapore English', in: A. Brown, D. Deterding and E.L. Low (eds), The English language in Singapore: Research on pronunciation, pp. 35-45. Singapore: Singapore Association for Applied Linguistics.

Goh, Chuen Meng Christine (2003). Applications of discourse intonation 1: Malaysian and Singaporean English. http://www.academia.edu/953242/Applications_of_ Discourse_Intonation_I_Malaysian_and_Singaporean_English (accessed 1 April 2013).

Gupta, Anthea F. (1992). 'The pragmatic particles of Singapore Colloquial English', Journal of Pragmatics 17-3:39-65.

Gupta, Anthea F. (2006a). 'Singlish on the web', in: Azirah Hashim and Norizah Hassan (eds), Varieties of English in Southeast Asia and beyond, pp. 19-37. Kuala Lumpur: University of Malaya Press.

Gupta, Anthea F. (2006b). 'Epistemic modalities and the discourse particles of Singapore', in: K. Fischer (ed.), Approaches to discourse particles, pp. 149-66. Amsterdam, Boston: Elsevier.

Hassan, Norizah and Azirah Hashim (2009). 'Electronic English in Malaysia: Features and language in use', English Today 100 25-4:39-46. http://jcmc.indiana.edu/volı/ issue2/huffaker.html (accessed 20 June 2013).

Hassan, Norizah, Azirah Hashim and Adriana Sufun Philip (2012). 'Language use in the construction of interpersonal relationships: Electronic English in Malaysia', in: E.L. Low and Azirah Hashim (eds), English in Southeast Asia: Features, policy, and language in use, pp. 325-42. Amsterdam: John Benjamins.

Kuang, Ching Hei (2002). 'The implications of 'lah', 'ah', and 'hah' as used by some speakers in Malaysia', Jurnal Bahasa Moden 14:133-54.

Kwan-Terry, Anna (1978). 'The meaning and source of the 'la' and 'what' particles in Singapore English', RELC Journal 9-2:22-36.

Kwan-Terry, Anna (1991). 'Through the looking glass: A child's use of particles in Chinese and English and its implications on language transfer', in: A. Kwan-Terry (ed.), Child language development in Singapore and Malaysia, pp. 161-83. Singapore: Singapore University Press.

Kwan-Terry, Anna (1992). 'Towards a dictionary of Singapore English: Issues relating to making entries for particles in Singapore English', in: A. Pakir (ed.), Words in a cultural context, pp. 62-72. Singapore: Unipress.

Lam, Phoenix (2008). Discourse particles in an intercultural corpus of spoken English. [Unpublished doctoral dissertation, The Hong Kong Polytechnic University, Hong Kong.]

Lee, Su Kim (1998). Manglish. Kuala Lumpur: Times Books International.

Lee, Tong King (2007). 'Pragmatic particles as speech strategies: The case of 'leh' and its tonal variants in Colloquial Singapore English', California Linguistic Notes 32-1:124. 
Leimgruber, Jakob R.E. (2013). Singapore English: Structure, variation, and usage. Cambridge: Cambridge University Press. [Studies in English Language.]

Leimgruber, Jakob R.E. (2016). 'Bah in Singapore English', World Englishes 35-1:78-97.

Ler, Vivien Soon Lay (2005). An in-depth study of discourse particles in Singapore English.

[PhD dissertation, National University of Singapore.]

Ler, Vivien Soon Lay (2006). 'A relevance-theoretic approach to discourse particles in Singapore English', in: K. Fischer (ed.), Approaches to discourse particles, pp. 149-66. Amsterdam, Boston: Elsevier.

Lim, Lisa (2007a). Singapore English is a tone language 'meh'? SE particles and the hybrid prosody of a contact variety of English. Edinburgh: Department of Linguistics and English Language, University of Edinburgh. [English Language Research Seminar Series.]

Lim, Lisa (2007b). 'Mergers and acquisitions: On the ages and origins of Singapore English particles', World Englishes 27-4:446-73.

Loke, Kit-Ken and Low Mei-Yin Johna (1988). 'A proposed descriptive framework for the pragmatic meanings of the particle 'la' in colloquial Singaporean English', in: B. McCarthy, (ed.), Asian-Pacific Papers, pp. 150-61. Wollongong: Applied Linguistics Association of Australia. [Occasional Papers 10.]

Low, Ee Ling and Adam Brown (2005). English in Singapore: An introduction. Singapore: McGraw-Hill.

Low, Ee Ling and David Deterding (2003). 'A corpus-based description of particles in spoken Singapore English', in D. Deterding, E.L Low and A. Brown (eds), English in Singapore: Research on grammar, pp. 58-66. Singapore: McGraw Hill.

Muniandy, Mohan K., Gopala K.S. Nair, Shashi K. Krishnan, Irma Ahmad and Norashikin B.M. Noor (2010). 'Sociolinguistic competence and Malaysian students' English language proficiency', English Language Teaching 3-3:145-51.

Ooi, Vincent B.Y. (2001). 'Upholding standards or passively observing language: Corpus evidence and the Concentric Circles Model', in: B.Y.V. Ooi (ed.), Evolving identities: The English language in Singapore and Malaysia, pp. 188-204. Singapore: Times Academic Press.

Östman, Jan-Ola (1982). 'The symbolic relationship between pragmatic particles and impromptu speech', in: N.E. Enkvist (ed.), Impromptu speech: A symposium, pp. 14777. Åbo: Åbo Akademi.

Pillai, Stefanie S. and Fauziah Kamaruddin (2006). 'The variety of Malaysian English used in radio advertisements', in: Azirah Hashim and Norizah Hassan (eds), Varieties of English in South East Asia and beyond, pp. 61-75. Kuala Lumpur: University of Malaya Press.

Platt, John (1987). 'Communicative functions of particles in Singapore English', in: R. Steele and T. Threadgold (eds), Language topics: Essays in honour of Michael Halliday, pp. 1, 391-401. Amsterdam: John Benjamins. 
Platt, John and Ho Mian Lian (1989). 'Discourse particles in Singaporean English: Substratum influences and universals', World Englishes 8-2:215-21.

Platt, John and Heidi Weber (1980). English in Singapore and Malaysia. Petaling Jaya: Oxford University Press.

Platt, John, Heidi Weber and Ho Chee Lick (1983). Text volume of Singapore and Malaysian English. Amsterdam: John Benjamins.

Schiffrin, Deborah (1987). Discourse markers. Cambridge: Cambridge University Press.

Shamsudin, Khatijah (2006). 'Slang expressions among Malaysian teenagers', in: Zuraidah Mohd. Don (ed.), English in a globalised environment: Investigating an emerging variety of English, pp. 325-44. Kuala Lumpur: University of Malaya Press.

Sperber, Dan and Deirdre Wilson (1995). Postface to the second edition of relevance: Communication and cognition. Oxford: Blackwell.

Wee, Lionel (2010). 'The particle 'ya' in colloquial Singaporean English', World Englishes 29-1:45-8.

Wong, Jock Onn (2004). 'The particles of Singapore English: A semantic and cultural interpretation', Journal of Pragmatics 36:739-93. 


\section{Appendix}

TABLE 1 Frequency of Malaysian English discourse particles

No. Discourse particles Frequency Percentage (\%)

\begin{tabular}{llrr}
\hline $\mathbf{1}$ & lah/la & 371 & 35.4 \\
$\mathbf{2}$ & lor/lo & 187 & 17.8 \\
$\mathbf{3}$ & leh & 132 & 12.6 \\
$\mathbf{4}$ & ma/mah & 86 & 8.2 \\
$\mathbf{5}$ & ah & 56 & $5 \cdot 3$ \\
$\mathbf{6}$ & wor & 37 & 3.5 \\
7 & meh & 36 & 3.4 \\
$\mathbf{8}$ & de & 36 & 3.4 \\
$\mathbf{9}$ & one & 20 & 1.9 \\
$\mathbf{1 0}$ & o & 19 & 1.8 \\
$\mathbf{1 1}$ & ya & 18 & 1.7 \\
$\mathbf{1 2}$ & wei & 11 & 1.0 \\
$\mathbf{1 3}$ & ke/kah & 8 & 0.8 \\
$\mathbf{1 4}$ & bah & 8 & 0.8 \\
$\mathbf{1 5}$ & what & 6 & 0.6 \\
$\mathbf{1 6}$ & hor & 6 & 0.6 \\
$\mathbf{1 7}$ & gua & 5 & 0.5 \\
$\mathbf{1 8}$ & geh & 5 & 0.5 \\
$\mathbf{1 9}$ & nah & 1 & 0.1 \\
$\mathbf{2 0}$ & kan & 1 & 0.1 \\
& & $\mathbf{1 0 4 9}$ & \\
& Total & & $\mathbf{1 0 0}$ \\
\hline
\end{tabular}


TABLE 2 Functions of Malaysian English discourse particles: reducing social distance

\begin{tabular}{lll} 
Discourse & Function & Examples \\
particle & & \\
\hline 1. lah/la & a) to agree in a friendly manner & i. Ok lah. \\
& b) to soften an order/advice & ii. Can lah. \\
& c) to express resignation or concession & i. You come to sg lah! \\
& ii. You see doctor lah. \\
& & ii. Forgive you lah since you got good \\
\end{tabular}

2. $\operatorname{lor} /$ lo

a) to express resignation about someone else's action or (own) belief

b) to indicate sincerity in expressing sympathy

c) to indicate that one understands the situation and has acted accordingly

d) to soften an order/advice

e) to tease in a playful manner i. Ya lo. I also don't want to go back to Penang.

ii. Since you're busy, forget about going to the mines $l o$.

i. I understand how you feel $l o$.

ii. U miss the call then missed liao lo ...

i. I thought you were doing your assignment so I didn't date you $l o$.

ii. Ya $l o$ ya $l o \sim$ agree with ben $l o \sim$

i. Don't call your 'gor gor' (brother) 'pui kia' (fatty), angry $l o$.

ii. You try to negotiate with him lo.

i. So next time I call you sexy lo since you have a sexy tongue.

ii. I think you must be collected from dumpside $l o$.

i. I cannot watch now leh. Got CCTV in office here.

ii. It's not the one that I want leh.

b) to soften a warning

i. You want me to sprain your leg? Very pain one leh.

ii. This is already the third time in a year you dye your hair liao leh.

c) to soften an order/advice

i. Intro to me leh.

ii. Don't dye your hair so many times leh.

iii. I'm waiting for you to belanja (treat) leh. 
TABLE 2 Functions of Malaysian English discourse particles: reducing social distance (cont.)

$\begin{array}{lll}\text { Discourse } & \text { Function } & \text { Examples } \\ \text { particle } & & \end{array}$
d) to give a compliment in a flattering tone
i. Your dog is cute leh.
ii. Package looks not bad leh

4. ma/mah a) to soften an order/advice

i. You should wait until holiday only dye your hair mah.

ii. Come on. Don't embarrass me in public mah.

5. ah a) to keep two interlocutors in contact/to indicate more is to follow in the conversation

b) to soften an order/request

c) to show surprise or disbelief i. TMD (damn) ah..tired of waiting for water to come.

ii. I got eat $a$ h.. more than my frens.. don worry $\mathrm{k}$ ? =)

i. You come back early $a h$.

ii. Let's go to Melaka $a h$ !

i. You are not going out $a h$ ?

ii. Really $a h$ ? So kelian!

6. wor

a) to soften a contradiction or disagreement i. You sure you want to take photos? I remember you always hide yourself wor.

ii. No wor. Not good to eat panadol. (I don't think you should take panadol.)

7. meh

a) to soften an expression of disbelief or disagreement i. You are sexy meh? (I don't think you are sexy.)

ii. A: Nobody will be here to welcome you.

B: Really meh? Bernard and Ping are quite free tomoro wat. (I don't believe you.)

b) to admit that one has made an incorrect i. You are not paid meh? (You mean you are assumption about others not paid?)

ii. tat one not DKAP meh? (That's not the DKAP?)

c) to correct another's wrong assumption about oneself in a gentle manner i. U think i am cooking a feast meh (You think I am cooking a feast?)

ii. ...is true ... haih ... tot like u meh, richman.. (You think I am rich like you?) 


$\begin{array}{lll}\text { Discourse } & \text { Function } & \text { Examples } \\ \text { particle } & & \end{array}$

8. de

a) to emphasize with the intention of rendering one's assumption as shared knowledge i. I can sponsor my place for you to stay de. (You know I will let you stay at my place.)

ii. Go wif ur heart lo but ur mum sure ask $\mathrm{u}$ to work 1st de. (We both know your mother is sure to ask you to find a job first.)
9. one

a) to emphasize with the intention of rendering one's assumption as shared knowledge (this particle has the same function as de) i. She's always late one. (You must know she is always late.)

ii. Then sure got some other thing one la. (You know there will be other problems.)

10. 0

a) to give advice in a friendly manner

i. Sleep early $o$.

b) to end a conversation in a friendly and polite manner

c) to emphasize with the intention of rendering it as shared knowledge

i. We will be having ввQ \& steamboat next week $o$.

ii. Kitty angry oledi $o$..

11. ya

a) to soften an order/advice

Remember to buy clothes for me $y a$.
b) to end a conversation in a friendly and i. Enjoy yourself $y a$. polite manner.
ii. Lu apasal? Take care ya. (What's up? Take care, ok.)

12. wei a) to ask a question politely

i. Next month you got go back to Malaysia ah wei? (Will you be going back to Malaysia next month?)
b) to make an assertion in a respectful
i. You're the boss wei. manner.
c) to soften contradiction or disagreement
i. Cannot go now wei.
ii. That one is broken la wei.

13. $\mathrm{ke} / \mathrm{kah}$ 
TABLE 2 Functions of Malaysian English discourse particles: reducing social distance (cont.)

$\begin{array}{lll}\text { Discourse } & \text { Function } & \text { Examples } \\ \text { particle } & & \end{array}$
14. bah
a) to indicate uncertainty in an assertion
ii. She will not come bah.
b) to challenge in a friendly manner
i. You confess your love to me in school bah! I need witnesses.

15. what
a) to express contradiction (while pointing out an obvious fact which the speaker

i. Very near what! You don't have to drive assumes the hearer should have known) there.

ii. We can get the tickets from the games we play what.
b) to contradict in a friendly manner
i. You are very charming what!
ii. I'm your friend what!

16. hor a) to soften an order/advice

i. Tomorrow you must wear a pretty dress hor.

ii. You fetch ML hor.
b) to soften an insensitive comment
i. You can also eat a lot hor. hor.
c) to seek an agreeable response i. Very cheap hor.
ii. Hehe ... very great event hor!!!

ii. You must be very bored staying at home

17. gua a) to indicate uncertainty in an assertion i. Bad tag means tagging other people without their permission gua ...

18. geh

a) to challenge in a friendly manner

i. You can also come now geh.

b) to seek sympathy

i. How come I dunno geh.

19. nah a) to soften an order/advice

i. Lend me your camera nah. (Do lend me your camera.)

20. kan

a) to elicit a form of agreement from the interlocutor i. Higher risk, higher return, kan? (Higher risk, higher return, don't you think?) 
TABLE 3 Functions of Malaysian English discourse particles: increasing social distance

$\begin{array}{lll}\text { Discourse } & \text { Function } & \text { Examples } \\ \text { particle } & & \end{array}$

1. lah/la

a) to show exasperation/unhappiness with

i. No lah! Your head lah! someone

ii. Next time next time ... Donno how many next time liao lah!

iii. Dr. Lau, my baby is a cat lah! Not a dog.

b) to contradict in a defensive tone, usually i. I meant 'dry swimming' lah!

by expressing the implicit assumption ii. I won't be around today lah.

that the hearer should know better

iii. I will upload the photos later lah.

iv. She's younger than me lah! Otherwise, I'll report to the police ASAP.

2. leh a) to contradict in a harsh manner

i. You are Hokkien meh? Even your mom doesn't know she's Xing Hua or Hokkien leh.

ii. I don't know where is he leh!

3. ma/mah a) to point out an obvious fact (which the speaker assumes the hearer should have known) i. Very easy mah. Just follow what they say. (It's so easy, don't you know!)

ii. It's Deepavali mah. So I can go Penang for three days. (Don't you know it's Deepavali?!)
4. meh

a) to admonish or challenge in a judgemental or hostile manner i. U bukan tengah exam meh? (Aren't you in the middle of an exam-you should be studying.)

ii. Cannot meh? (You have a problem with that?)

5. ke/kah a) to express sarcasm or disbelief i. Your wound is very serious $k e$ ? (Is your wound so very serious?)
6. what

a) to seek to have one's way in an argument by making one's assertions appear as the obvious truth. i. Very near what! You don't have to drive there.

ii. We can get the tickets from the games we play what. 